\title{
Digitization of African Public Diplomacy: Issues, Challenges and Opportunities
}

\author{
Floribert Patrick C. Endong \\ University of Calabar, Nigeria
}

\begin{abstract}
The ubiquity of the Internet and the social media has given birth to a plurality of digital and postmodern cultures in the world in general and Africa in particular. Among these cultures (which range from e-commerce to e-government), African digital diplomacy has for years remained understudied by Afro-centric scholars. Much - if not the greatest part - of the literature on the topic focuses on the activities of Western governments, MFAs and diplomatic missions glaringly overlooking those of their African counterparts. This literature also tends to overlook or downplay the effects of some recent socio-political developments (notably the COVID-19 pandemic and the acceleration of the smart city/society concept) on African digital diplomacy. In a bid to fill this apparent gap in knowledge, the present paper shows how the digitization of public diplomacy is remarkably evolving in Africa amidst challenges and some positive developments. Hinging on secondary sources and critical observations, the paper specifically $x$ rays the challenges and opportunities of digital diplomacy in Africa. In the first place, the paper provides a critical exploration of the state of African digital diplomacy. In the second place, it examines the challenges faced by digital diplomacy in the continent; and in the third place, it addresses the opportunities of African digital diplomacy.
\end{abstract}

\section{Introduction}

The advent of the Internet and the social media has remarkably revolutionized most, if not all human industries. From business and education through social movements to administration, virtually all key forms of human industries on earth have phenomenally migrated to the Internet. This development has given birth to a plurality of digital cultures (notably e-commerce, e-government, ebanking, online education and hashtag activism), and has made conditions favorable for digitization and ICTs-based solutions to man's problems to become the talk of the town in countries across the world. This growing digitization coupled with the popularization of ICTs-based solutions to man's problems is even the "new normal" and perhaps one of the most powerful "religions" prevailing in today's world, as seen in the growing popularization - nay universalization - of such postmodern concepts as smart cities, the smart society and AI-based developmental concepts in countries across the planet.

The recent outbreak of the COVID-19 pandemic seems to have coincidentally magnified this apparent mania for the Internet, digitization, AI-based paradigms and smart cities/society concepts in the world. This is so as the COVID-19 pandemic seems to have convinced humanity that shifting to the digital is the principal - if not the best - approach to saving lives and economies on planet earth. In effect, the COVID-19 pandemic came with serious and unprecedented existential equations that justified already established Internet-based paradigms such as online education, e-banking, e-marketing, e-petition, e-government and other digital cultures. The unprecedented travails orchestrated in most modern societies by the COVID-19 pandemic forced nearly all aspects of human life on earth to shift online, from the simple and usual socialization cultures (birthday and marriage celebrations for instance), to concerts, social protests, academic conferences and multilateral meetings. In the face of the pandemic, even African governments that had, for the most part, appeared reticent, hostile or phobic to some sophisticated digitally driven approaches to administration and education, saw no option other than embracing digitalization with trepidation and with the modest hope of saving their respective economies and the lives of their citizens.

The domain of diplomacy has not been left untouched by these plural mutations and recent global movements in favor of digitization and data-based panaceas to man's problems. One proof of this thesis is that, the concept of digital diplomacy (also known as e-diplomacy or virtual diplomacy) has since 2001 become a received idea in most parts of the world, particularly in the west. The concept is actually a postmodern tradition that is presently transforming the practice of diplomacy and which is begging for increased scholarly attention. In line with this, Hockin and Mellisen note that digital diplomacy has brought with it "newness" in the field of diplomacy [1]. This newness has affected the core functions of diplomacy including negotiation, representation and communication. Diplomats and diplomatic missions are, as a result, compelled to adjust their "analogue" habits in order to be at breast of the ongoing Internet driven mutations in the world and to be relevant in the new information sphere. These adjustments are, 
according to Hockin and Mellisen, too complex that such terms as "digital diplomacy", "virtual diplomacy", "data-diplomacy" and "e-diplomacy" often used to describe them (the changes from analogue to digital habit among diplomats) - appear somehow insufficient or kinds of euphemisms. Hockin and Mellisen write:

[the adoption of "digital" habits] takes time, and for technological enthusiasts to simply proclaim the arrival of a 'new statecraft' in the form of what is variously termed e-diplomacy, digital diplomacy, cyber diplomacy and 'twiplomacy' is too simplistic. Paradoxically, greater complexity encourages Nescafé-school analyses and the search for simple explanations about what is happening to diplomacy as the regulating mechanism of the society of states. As in other epochs of fast technological change, the lure of quick fixes addressing multifaceted processes of change in diplomacy appears almost irresistible at the opening of the 'digital age'. [1, p.9]

Thus, according to the above scholars, the term digital diplomacy is just an attempt to simplify a phenomenon which is more complex and encompassing. Better, it (the concept of digital diplomacy) represents humanity's tendency of putting technical concepts in rather simple terms to ensure greater understanding of the complex changes the world is everyday witnessing or undergoing.

By implication, one may say it is hard to advance a universally accepted definition of the term "digital diplomacy". However, to facilitate discussions in this paper, e-diplomacy will be construed as the growing use of information and communication technologies (ICTs) and the social networking sites by countries of the world in a bid to achieve their respective foreign policy goals and practice public diplomacy. If digital diplomacy enables countries to practice their public diplomacy, it means it aims among other things at facilitating countries' communication with foreign publics in view of (i) accomplishing their foreign policy goals and (ii) creating such positive climate among these publics that can facilitate the acceptance of their respective policies. In line with this, digital diplomacy is not only the act of using a new medium (the digital technologies) to communicate with foreign publics and conduct diplomacy. It is also a means to the establishment of a diplomacy of greater proximity. Indeed, through digital diplomacy, a diplomat may perhaps through their Twitter account or Facebook profiles - establish a dialogue between him/her and foreign publics. This is feasible through responding constantly to posts on their Twitter or Facebook profiles. Such dialogue is of course, more strategic than the monologue of Public Diplomacy which most often happens in contexts where "analogue" approaches to diplomacy are applied.
The dialogue is also more strategic than the monologue as it offers greater opportunities for interactions with foreign publics, a situation which is susceptible to facilitate the establishment of stronger relationship between the digital diplomat and foreign publics. Sharing corollaries, Al-Muftah, Weerakkody, Rana, Sivarajah and Irani construe digital diplomacy as:

The use of technology by nations to define and establish diplomatic goals and objectives and to efficiently carry out the functions of diplomats. These functions include representation and promotion of the home nation, establishing both bilateral and multilateral relations, consular services and social engagement. It encapsulates the adoption of multiple ICT tools over the Internet to support a nation's interests in other countries while ensuring that foreign relations are improved between the countries. [2, p.502]

Digital diplomacy is a global phenomenon but the dominantly Euro-centric character of the available literature tends to suggest that the concept of African digital diplomacy is more a myth than a reality. In effect, most of the scholars [see 1, 3-7] who have delved into discussing e-diplomacy focused their attention on the west (the activities of western MFAs and embassies), devoting very little attention to Africa. Even Africa digital diplomacy scholars such as Adesina [8], Nweke [9] and Mvai [10] have addressed issues related to this diplomatic trend/revolution in rather general terms, subtly downplaying the African experience. In tandem with this, the state of digital diplomacy in the African continent is by and large still a less explored path or rather, a less travelled road. It thus goes without saying that African digital diplomacy remains a good topic for reflection and discourse.

In this paper attention will be focused on showing how digital diplomacy is evolving in Africa amidst challenges and amidst remarkable efforts by specific countries and political leaders towards fostering it. Using secondary sources and some critical observations, the paper specifically $\mathrm{x}$-rays the challenges and opportunities of digital diplomacy in Africa. Following this objective, the paper is structured into three main parts. The first section provides a critical exploration of the state of African digital diplomacy. The second section examines the challenges faced by digital diplomacy in the continent while the last section addresses the opportunities of the phenomenon.

\section{African Digital Diplomacy: A Brief Overview}

As earlier mentioned, digital diplomacy has since the mid-2000s become a global phenomenon attracting the attention of politicians, international relations pundits and scholars from a variety of 
disciplines. However, the available scholarship on the issue tends, by its mainly Euro-centric character, to suggest that the phenomenon is essentially western. Such literature also tends to intrinsically naturalize the myth stipulating that, while the west has remained the hottest spot of digital diplomacy, Africa continues to seriously lag behind and that, the continent is still yet to cover the first miles in the march towards the digital diplomacy Promised Land. That Africa is lagging behind in terms of Internet and social media penetration, openness to democratic values and traditions as well as in terms of technological innovations is a myth which has a degree of veracity and pertinence. But when it comes to the adoption of globalised Internet-based cultures and paradigms, the continent has since the mid 2000s struggled albeit insufficiently to "do like the rest of the world" and to "be like the west". Through this observable culture of copying ideas from the west or the rest of the world, a number of African governments have embraced digital diplomacy as early as in the mid 2000s [11-12]. Today, from Kenya and South Africa through Mali and Namibia to Rwanda, digital diplomacy has become a received idea in the African continent. The concept is therefore not new to governments, diplomats and diplomacy scholars within the continent. A number of research works indicate that African MFAs have en masse migrated to social networking sites. According to Ilan Manor many of these MFAs are as active on online platforms as their western counterparts $[11,13]$. This, according to the Manor, is evidence suggesting that the first order digital divide between Africa and the rest of the world is considerably narrowing.

Another 2015 study carried out by Kampf, Manor and Sergey, sought to empirically establish the fact that although African countries generally have a low Internet and social media penetration (ranging between $1.9 \%$ in Rwanda to $47.3 \%$ in Kenya), their MFAs operate websites, Facebook accounts and Twitter channels in view of achieving their foreign policy goals [14]. These African MFAs attract audiences to their social media account in the same ways the western counterparts do and in some cases, they even demonstrate greater online activity than their Western counterparts. The study revealed that as at the time of the investigation, Ethiopia's MFA had 34.6k followers on twitter; Kenya's MFA enjoyed 52.8k followers while Rwanda's MFA had 16k followers. The result of Manor's investigation somehow confirmed an earlier study he carried out the same year with two of his peers, in view of comparing three African countries' MFAs and their counterparts from Poland, the United Kingdom, America and France among other nations, this in terms of use of Social Networking Sites (SNSs) for diplomatic purposes. The study revealed that:

African MFAs [considered in the study] were found to be among the most active on SNS, suggesting a narrowing of some aspects of the digital divide. While African countries may lag behind Western countries in terms of internet penetration, computer infrastructure and internet accessibility, African governments seem to be equally active and as committed to engagement as their Western counterparts, if not more so. [14, p.13-14]

Kampf, Manor and Sergev's survey - like many other studies done by afro-positivist scholars - tend to paint a positive picture of African digital diplomacy; but the truth remains that all is not well with ediplomacy in the continent. Many studies rather reveal myriads of problems in the sector that beg for urgent attention [8, 12, 15]. In effect, despite the growing penetration of social media and the Internet in the continent, African digital diplomacy is yet to really catch on, or to be very vibrant. Since the year 2013, the continent has appeared as the fastest growing region in terms of mobile band [16]. The continent has also witnessed a growing number of MFAs which leverage the Internet and the social media for diplomatic purposes. Yet, many African leaders and diplomatic missions still do not have Facebook, Twitter or Instagram accounts. Also, many African governments and countries are not online. Some even seem to still be phobic to sophisticated forms of digital diplomacy.

A 2019 survey conducted by Twiplomacy, reports efforts by specific African leaders such as Kenya's Uhuru Kenyatta, Ghana's Nana Akufo-Ado and Rwanda's Paul Kagame towards using social media platforms such as Twitter, Facebook and Instagram for diplomatic motives [17]. The study reveals that while the Kenyan president has a very large number of followers on Twitter (7 Million followers), Rwanda's Paul Kagame is amongst the most conversational on Twitter. Kagame has 2.5 Million followers on Twitter, Facebook and Instagram combined. The same study reports that Ghana's Akufo-Ado has $421 \mathrm{k}$ followers on Instagram. If the three leaders mentioned above exemplify the class of African leaders who are digital diplomacy enthusiasts, many of their counterparts continue to lag behind in the use of the most basic forms of digital diplomacy. Twiplomacy notes for instance that the leaders of Eritrea, Mauritania and Swaziland are not on Facebook [17]. A related deplorable fact is that, the MFAs of many other African countries use the social media in a way which is rather mundane and not exclusively for foreign policy and diplomatic communications. In most cases, communications initially conceived for the consumption of domestic publics are used for diplomatic purposes when needs arise.

The current COVID-19 pandemic is, to an extent, one of the recent events which more or less paradoxically, have been a blessing to African digital diplomacy. The travails, restrictions and models of 
social distancing engendered by the pandemic seem to have forced virtually all African countries' MFAs, embassies and diplomats to accept to go through the great trek of digital diplomacy. Even countries which had most often been lukewarm or phobic to the use of sophisticated forms of digital diplomacy seem not to have had any better choice but to make digital diplomacy one of their premier public diplomacy "fetishes". In tandem with this, African presidents, diplomats and MFAs have with trepidation, learned to integrate digital tools to their modus operandis. These last months, most of them have for instance been forced to design their bilateral or multilateral meetings in virtual mode. Thus, concepts such as virtual conferences, virtual meetings and teleconferencing have "overnight", and due to the unpredictable constraints of the Corona pandemic, become more standard ways of designing negotiations and communication forums. An egregious illustration of this prompt resort to sophisticated forms of digitally assisted negotiation and communication forums is the Extraordinary Session of the ECOWAS Heads of State and Government which held on the 22 to 23 of April 2020. This conference was held through teleconferencing [18]. Another good example is the Heads of States Consultative Meeting of the East African Community which was similarly held through teleconferencing on May 12, 2020 [19]. Other examples include South African president Cyril Ramaphosa who attended the March 2020 edition of the G20 Summit not physically but virtually.

Thus, the COVID-19 pandemic somehow forced African countries' leaders, diplomats, embassies and MFAs to leap into an era of digital diplomacy, embracing en masse and with trepidation, Internetbased traditions (notably virtual meetings and virtual multilateral conferences) that had long ago become common in western countries. The pandemic thus enabled African countries to quickly conduct a diagnostic of their diplomacy and to somehow see the urgent need for greater efforts towards a more entrenched practice of digital diplomacy on the continent. The simple fact that most African critics and even diplomats described African MFAs and embassies' prompt resort to paradigms such as virtual multilateral and bilateral meeting and virtual conferences as a kind of novelty or as an unprecedented change should tell one that African diplomacy has for years been stuck into the old paradigm-based use of conventional channels. It therefore goes without saying that even though African countries seem to have been "conscientized" or "reformed" by the COVID-19 pandemic towards seeing the imperative to fully adjust and be at breast of the current digital revolution, all is still not well with African digital diplomacy. The industry faces numerous challenges that will be addressed in greater details in the following section of the paper.

\section{Challenges of African Digital Diplomacy}

It is hard to see a cultural revolution or a technological innovation which is totally problem free or which does not give birth to some mitigated issues. In line with this, digital diplomacy has been faced with a myriad of challenges in the west the same as in Africa. In this section four principal challenges to digital diplomacy in Africa will be x-rayed. These challenges include poor policy formulation, low Internet penetration and rural-urban digital divide, digital illiteracy among MFAs and low democratic culture.

\subsection{Poor Policies and Negative Attitudes towards Digital Diplomacy}

Authors such as Hockin and Mellisen [1], Flanagan [5] Stanzel [20] and Benyam [21] describe digital diplomacy as a kind of "disruptive innovation"; disruptive in the sense that it entails constant and unprecedented changes dictated by the most current innovations in information technologies. It also entails adjustments that will, among other things, require a high degree of flexibility from States, diplomats and MFAs. As noted by the Digital Diplomacy Review, e-diplomacy is a process of transformation which is dictated by a digital zeitgeist and which necessitates constant dynamism in MFAs and embassies' attitude towards sophisticated forms digital culture. The Review actually concedes that:

Digital diplomacy', is a means to

"understanding disruption". In an era of disruptive innovation, [...] rapid technological change, ubiquitous connectivity, big data, machine learning, algorithmic governance and digital literacy; diplomats, leaders and ministries started adopting what the digital zeitgeist necessitates: transformation. In the process of digital transformation, some political leaders and MFAs which are early adapters, geeks and quick learners seem to lead the way. [21, p.11]

From many indications, African MFAs, embassies and Heads of States have for the most part lacked the dynamism and flexibility needed to keep pace with new digitally driven cultures in the domain of diplomacy. In an era of supersonic digitally driven changes, many are slow, unsure and even still phobic to very sophisticated forms of digital diplomacy. While some of them negatively distinguish themselves by their online absence, others are simply not very active on social media. In 2019 for instance, a survey conducted by Twiplomacy revealed that Eretria, Namibia and Swaziland were not on Facebook [17]. The same survey revealed that only few African leaders (notably Paul Kagame of 
Rwanda, Nana Akufo-Ado of Ghana and Uhuru Kenyatta of Kenya are either very active on social media and/or have millions of followers on such networking sites as Facebook, Twitter and Instagram. The same handful of African presidents and MFAs keeps on being rated high in Twiplomacy survey (as seen in the observer's 2015 survey), while the bulk of other diplomatic institutions of the continent remains less susceptible to adopt innovative and sophisticated forms of diplomacy.

Many of these slow-to-change African MFAs and embassies create Facebook, Twitter and Instagram account but are less or not conversational on social media platforms. Other do create websites which are just poorly designed and incidents of digital diplomacy on these online platforms mostly happen in flashes. In line with this, Adesina rightly observes that although African foreign ministries are struggling to be present and active online, "the percentage of African countries maximizing the potentials of digital diplomacy is negligible. Many African leaders do not have Facebook or Twitter accounts" [8, p.7]. The 2017 to 2019 reports of Twiplomacy share corollaries [17].

All the evidence mentioned above tend to suggest that there is still need for African countries to review their digital diplomacy policies or attitudes. The case of African countries that are totally absent from online platforms or which do not have Facebook, Twitter and Instagram accounts (see Eretria, Namibia and Swaziland discussed above) could, to an extent be viewed as a sign pointing to the truism that, African diplomats are rather retrograding or lagging behind as far as being at tune with our digital world is concerned. They give the impression that they have much to learn from contemporary rock stars, celebrities and socialites (including those of African descent) who leverage the social media expertly and have tens of millions of followers on such online platforms.

\subsection{Poor Training and Digital Illiteracy among African Diplomats}

The emergence of digitization in virtually all sectors of human life on earth warrants that training in all domains of human endeavor integrates modules in digital literacy or digital fluency. The field of diplomacy is no exception. As noted by Flanagan, "the iGeneration has more opportunity than any generation before to understand the[ir] world, to engage with the[ir] world and to shape the[ir] world" [5, p.9]. In line with this, the diplomat is compelled to develop the "reflexes" of the iGeneration to survive and be relevant in the domain of diplomacy. That usually comes as a consequence of effective training which may enable him or her (the diplomat) be a digital migrant, what Flanagan calls the "Naked diplomat". Flanagan writes: "the Naked Diplomat has a smartphone to protect his modesty. But also the skills that have always been essential to the role: an open mind, political savvy, and a thick skin. He or she will learn the language of this new terrain in the way he or she has learnt Chinese or Arabic" [5, p.10].

In many African countries the training of diplomats does not always integrate capacity building in the use of the ICTs. Meanwhile, these diplomats are mostly not of the iGeneration, (to employ Flanagan's terms) or digital natives. In a largely conceptual study carried out on the training of African diplomats, Manor observed this problem and presents it as the root of a second order digital divide between African diplomats and their counterparts from the West [11]. Manor specifically contends that staffers at most African countries' MFAs (particularly those representing very poor countries) do not have sufficient familiarity with the online environment and so, have a very limited digital fluency or literacy. This reduced digital fluency hampers their effective leverage of digital diplomacy. As Manor puts it, contrary to staffers at the UK Foreign Office who may have (i) had access to the Internet for more than two decades, (ii) opened a Hotmail email account while they were in Middle School and (iii) even used PCs throughout most of their education, most MFA staffers in smaller and poorer African nations may still "find it harder to fully harness the potential of social media and use it as an effective tool for information gathering and policy making" [11].

Worse, the study of digital diplomacy as a course is still either a mirage, a dream or a yet to be received idea in most African countries. In effect, the teaching of digital diplomacy seems for the moment, to be an idea African diplomacy scholars are yet to strongly push for. In a paper devoted to how the COVID-19 pandemic has turned out to be an opportunity for African digital diplomacy, Wekesa shares corollary as he contends that there is a need for the inclusion of digital diplomacy courses in cognate university degree programs in African universities [15].

\subsection{Digital Divide}

The African continent has witnessed a remarkable Internet and social media penetration these last years (this will be treated in greater details in the sub-section devoted to opportunities). The continent has also witnessed a growing number of African foreign ministries and embassies embracing the Internet and the social media such as Facebook, Twitter and Instagram to achieve their foreign policy goals. In spite of these positive developments, the percentage of African nations maximizing the potentials of digital diplomacy is relatively low for reasons which among other things, include digital divide.

By definition, the term digital divide refers to a situation where there are inequalities in access to, and/or ability to use information and communication 
technologies. This divide may be between countries, continents and people in a national territory. The digital divide concept points to the myth that the Internet has not evenly spread to all the sub-regions of the world. The concept is made plausible by the fact that Africa has these last years had the lowest Internet penetration [22]. Apart from countries such as Kenya, Rwanda and South Africa which have made efforts to narrow the gap between Africa and the other parts of the world in terms of Internet penetration, most countries within the African continent have had penetrations that hardly exceed $30 \%$. The rate of Internet penetration in Africa remains the lowest in the world as it is estimated at $26.5 \%$ compared to $70.5 \%$ and $87.7 \%$ respectively in Europe and North America [22]. In the same line of argument, the ITU's 2019 Measuring Digital Development states that only 28.2 per cent of Africa is online [23]. The report adds that such Internet presence or use is the lowest in the world. Still in guise of showing the gloomy state of Internet penetration in Africa, the report adds that Africa's offline population is about $71 \%$ compared to Europe's own which is $17.5 \%$.

What makes the above scenario worse is the fact that, the digital divide between rural and urban regions is even accentuated in African countries. In tandem with this, Mahler, Montes \& Newhouse state in their World Bank commissioned report titled Internet Access in Sub-Saharan Africa that rates of Internet access are generally lower in localities situated outside the capital cities of African countries [16]. The trio of researchers attributes these low rates of Internet access in rural zones to lack of access to electricity particularly among poor rural dwellers. Another reason justifying the low Internet penetration in both rural and urban regions in the continent is the low levels of Internet affordability coupled with the relatively reduced level of political will to arrest this low Internet affordability issue. In effect, Internet affordability has since the early 2000 remained low in the continent. In 2017 for instance, Dahir lamented this Internet un-affordability issue noting that in many African countries (notably Mali), national broadband plans either sit unendorsed while in other nations, (notably the Gambia), they are outdated [24]. Dahir also observed that out of 58 African countries, only Mauritius featured in the top 10 of the index tracking "affordability drivers". Internet connection has since the early 2000s not been affordable for most Africans. Honorary Chair of Alliance for Affordable Internet (A4IA) shares corollary thus:

While it is heartening to see the progress made by some [African] countries on the Affordability Drivers Index, overall, the results make for disappointing reading. The low scores across the board show just how far we [are] left to go toward developing and putting into place the policies necessary to reduce broadband prices and expand access. Yet progress is possible — countries like Rwanda are testament to this. [22, p.3]

Most if not all African MFAs and embassies have access to the Internet as well as the abilities to finance Internet-based strategies to achieve their foreign policies goals. Thus, Internet penetration does not really reflect the volume of African MFAs' online activities. However, the level of Internet penetration gives a clue about the size of pockets of their citizens that may be reached through online-based communication strategies. It also gives observers an idea about the size of African audiences that may be reached by Africa-based embassies through online communication strategies. It goes without saying that if the Internet affordability remains low in Africa, less people will continue to have access to the Internet and the size of possible receptors of African MFAs' online communications will continue to be reduced. Also, it is fair to speculate that if rural-urban digital divide continues to widen, the possibilities for African MFAs and embassies to communicate with African publics will be confined to urban internautes. Thus, the digital divide and low Internet affordability in African countries are susceptible to affect or reduce the effectiveness of the Internet-based public outreach strategies deployed by Africa MFAs and embassies.

\subsection{The Absolute Top-Down Process of Public Diplomacy}

Two of things that make digital diplomacy an uneasy game are the facts that (i) e-diplomacy requires MFAs and embassies to react on events on the fly and (ii) it is fraught with uncertainties. We are in era arguably considered as a time of post truth. Rumors and disinformation nowadays abound and move much faster today than 10 or 20 years ago. MFAs and embassies are more than ever, compelled to get ahead of events and act fast to avoid communication gaps that may lead to misunderstanding and negative perceptions of MFAs' activities and negative reactions from foreign publics. Foreign publics now expect embassies and governments to act promptly to clear doubts among foreign and diasporic publics as well as to redress grievances and satisfy these publics' demands. This can really be possible when government and MFAs adopt liberal policy-development processes such as the "open policy formation" which Heinbecker and Palamar describe in the following terms:

This approach consciously tries to bring citizens into the foreign policy-making process, recognizes that there are good ideas and smart people outside of government as well as inside, seeks to tap into outside sources of expertise and tries to develop an innovative culture within government. This is accompanied by a similar process within departments, which involves breaking down hierarchies and silos, 
and encouraging colleagues with relevant expertise and experience from across the department (and even from across the entire government) to collaborate on projects. [6, p.9] Contrary to making the "open policy formation" doctrine the centre piece of their modus operandis, most African countries' MFAs and embassies tend to follow a to-down process in pursuit of their public diplomacy goals. By such a process, the government fully controls the country's diplomatic narrative and mostly does not allow the embassies or diplomats to talk on their own on issues concerning the country and its foreign policy. Such model of policy formation does not also permit unauthorized communications by junior staffers of the MFAs even when senior staffers have a degree of freedom to express their positions on issues regarding the country. In such conditions, foreign ministers and embassies' communications on burning issues are most often retarded as most governments are often too careful not to divulge an information that may be prejudicial to their country. During the 2015-2016 Ebola in Sierra Leone and Liberia for instance, it was observed that the Liberian and Sierra Leonean MFAs and embassies to European countries were very slow in revealing information about deaths and the magnitude of the outbreak in their countries of origin. This made conditions favorable for the proliferations of rumors and conspiracy theories that fuelled waves of fear and epidemics of panic among Sierra Leonean and Liberian Diasporas in the west [25].

Another example happened in the ending part of the year 2016 with the "mysterious" disappearance of the then Malawian president Peter Mutharika. The president left his country in view of attending a United National General Assembly meeting scheduled to be held in mid September and only returned to his country on November 6 of that year, after waves of rumors around his death had already instill mistrust of his government in the hearts of both the domestic public and the Malawian Diaspora. The mysterious circumstances surrounding Mr. Mutharika's disappearance and the failure by his communications team to reveal his itinerary and whereabouts fuelled social movements such as the \#BringBackMutharika hashtag. These movements which were initiated and supported by both the national public and the Malawian Diaspora illustrated the negative side of the absolute top-down process of public diplomacy.

\subsection{Authoritarianism and Anachronistic Cyber Legislations}

Digital diplomacy has more chances to thrive in a country where there is a relatively high democratic culture. As noted by Rashika, democracy is both an enabler and one of the goals of digital diplomacy [26]. Indeed, digital diplomacy aims at "the creation of technologies to keep the internet free and open". It has the related objectives "of promoting freedom of speech and democracy as well as undermining authoritarian regimes" [26, p.77]. In most African countries however, digital diplomacy - the same as egovernment and internet-based advocacy - is most often hampered by authoritarianism often manifested through the passing of anachronistic cyber laws or the institution of stringent cyber censorship which ultimately limit publics' access to the Internet and the social media. At various points in time, African governments have fantasized over controlling or regulating the Internet in a way as to asphyxiate online movements (citizen diplomacy) aimed at criticizing them. They have also tended to discourage movements aimed at popularizing political ideas (notably same sex marriage, LGBT proselytism) that are concurrent to mainstream thinking and popular cultural doctrines in their territories.

One way through which African governments have often autocratically suppressed citizen diplomacy is the institution of ad-hoc Internet shutdowns and the political intimidation of bloggers and political activists who dare criticize the government on online platforms. Such moves have been observed in Cameroon in 2011 and 2017. In the wake of the Arab spring, the Cameroonian government shut down Facebook and Twitter in a bid to stultify social movements which were still at an embryonic stage in its territory. In 2017, a separatist movement led by the Anglophone minority sprang up and leverage the Internet to spread controversial and sensational messages against the Cameroonian government. Once more, the Cameroonian government resorted to Internet shut downs in the English speaking zones of the countries in a bid to curtail the spread of what it presented as hate speech, fake news and unfounded criticism against it (the government). Similar scenarios of Internet shutdowns and muscled Internet censorship were also observed in Nigerian in 2015 as well as in Ghana, a country which ironically, is often considered as a model in terms of democracy on the African continent [24, 27 $28]$. These muscled ways of censoring the Internet and of controlling social media communications affects the smooth practice of digital diplomacy in Africa.

\section{Opportunities of African Digital Diplomacy}

African digital diplomacy is not only faced with challenges. Indeed, the digital culture has various prospects in the continent. Here, attention will be given to four of such prospects including (i) the growing popularity of the myth of smart society, (ii) the growing Internet penetration in the continent, (iii) the smartphone revolution and (iv) the rise of the post truth era. 


\subsection{The Acceleration of the 'Smart Society' Concept in Africa}

A number of recent developments in the world such as the ubiquity of ICTs and digitization, the new progresses in the domain of artificial intelligence (AI) and the introduction of G5 among others have come to give greater credence to the 'Smart City/Society' myth. By this myth, the world is progressively becoming a "smart environment", with countries of the world becoming smart societies and their urban spaces, smart cities. This follows the premise that "smartness" has been achieved in various key domains of life on earth, as seen in concepts such as smart agriculture, smart schools/learning, smart car and smart building among others. This also follows the conception of smart city developments such as the Giga projects under construction in Saudi Arabia, the Masda in Abu Dhabi, the Smart Japan ICT Strategy and the Smart Thailand 2020 among others.

By definition, a smart society is a way of reimagining the urban space. The term concretely refers to the use of very sophisticated technologies and data analytics to make cities and countries more suitable and efficient. According to the ITU, it is "the state where the quality of citizens and efficiency, productivity and competitiveness of society get dramatically improved via a widespread use of advanced ICT such as mobile, sensing, artificial technologies" [29, p.1]. Smartness in this context entails at least four principal things: (i) the adoption of autonomous operation via a sensing technology, (ii) the adoption of artificial intelligence via a machine learning technology, (iii) the delivering of ubiquitous services at any time and any place via mobile technology and (iv) the provision of user-centric services through constant communication between providers and consumers.

Like in other regions of the world, the smart society concept has of recent become popular in Africa thanks to a plurality of specific projects. One of such projects is the Smart Africa Initiative which was born out of a summit held in Kigali (Rwanda) in 2013. The Initiative culminated in the adoption of the Smart Africa Manifesto document by 7 heads of States (namely Rwanda, Kenya, Uganda, South Sudan, Mali, Gabon, Burkina Faso) and which was later ratified in 2014 by the remaining African Heads of States at the General Assembly of the African Union. As stated in its Manifesto, the Smart Africa Initiative aims to:

i. Put ICT at the centre of national socioeconomic development agendas of Member States;

ii. Improve access to ICT especially broadband;

iii. Improve accountability, efficiency and openness through ICT promoting the introduction of advanced technologies in telecommunication;

iv. Put private sector first; and

v. Leverage ICT to promote sustainable [30].

Thus, the Initiative highlights policy, access, egovernment, private sector/entrepreneurship and sustainable development as the five pillars which are to be based on the use of the ICTs. The Smart Africa Initiative has reverberated through the efforts of countries such as Rwanda which for some years now has introduced ICTs in almost all vital sectors of its economic including diplomacy, in order to ameliorate the lives of its citizen. Concretely, Rwanda has embraced the smart city/society concept by introducing the $\mathrm{Wi}-\mathrm{Fi}$ in public transportation, the cashless payment in public transport as well as by launching its e-government platform called Irembo through which Rwandans have been enjoying essential public service. In addition to this, the country has popularized the use of mobile money applications to pay for water and electricity as well as for the payment of taxes. Such introduction of the digital has also been seen in the domain of Rwandese diplomacy [10].

Of recent, the COVID-19 pandemic has revived the smart Africa myth, motivating governments from Rwanda to Cameroon and from Senegal to Nigeria to give a greater attention to the application of the ICTs in key sectors of their economies, from education through banking to diplomacy. The COVID-19 pandemic actually galvanize these countries to seriously seek or to at least view the need to overcome the various barriers to the application of ICTs in key domains of their economies and to find creative multidisciplinary methodologies to make smart society principles the foundation of their socioeconomic development. In various parts of the continent (notably Cameroon and Nigeria) governments fantasized over introducing/fostering online education, smart schools and distance learning during periods of school closure, in a bid to save school years in their territories. In the domain of diplomacy, the same growing enthusiasm towards the use of more sophisticated forms of digital diplomacy was observed. Wekesa rightly observes that the COVID-19 pandemic contributed in turning the challenge of the limited application of ICTs in African diplomacy to an opportunity. The pandemic triggered a sudden and "conspicuous uptick in digital diplomacy" [15]. It plunged many African nations "into the deep end of the digital diplomacy pool". All these developments are unusual, but positive developments in the African diplomatic landscape. They indicate that, with sufficient political will, African countries can rapidly adapt to the disruptive "new normal" of global diplomacy. The developments are also evidence showing that the 
acceleration of the smart city concept is an opportunity for the growth African digital diplomacy.

\subsection{Growing Penetration of the Internet and the Social Media}

The digital divide between Africa and the West persists and has continued to be interpreted mainly as an indication that Africa is still lagging behind in terms of Internet and social media penetration. According to a recent report published in 2019 by the ITU, Africa is the continent with the lowest Internet usage rate [23]. It is also the continent with the lowest number of mobile phone ownership. Thus, from a comparative perspective, Africa still needs to make considerable efforts to enjoy the kind of Internet and social media penetration presently prevailing in the West or the rest of the world. However, the above scenario does not cancel the fact that over the years, levels of Internet and social media penetration in Africa have been rising. According to Kemp, Africa has witnessed the fastest growth rates in terms of Internet penetration in recent years [31]. This has been so as the number of Internet users across the continent has been increasing by more than $20 \%$ year-on-year. According to the Internet World Stats, Africa numbered an estimate of 522,809,480 Internet users by June 30,2019 . This number corresponds to a $39.6 \%$ Internet penetration in the continent and an $11.48 \%$ Internet growth since the year 2000 . The same institution observes that Facebook users in the African continent could be estimated at 204,304,118 as at June 30, 2019 [32]. In the same line of thought, the Digital 2020 Global Overview Report estimates the number of African using the Internet at $33 \%$ of the continent's total population [33].

Besides the growing Internet penetration in the continent, there is a growing social media penetration supplemented by rising mobile connectivity. Internet World Stats notes for instance that Facebook penetration rate in the continent from June 2000 to June 2019 has been at $15.9 \%$ [32]. This trend has also been observed by Fraser-Molekivi and Senghor who conceded that as of 2009, over 40 percent of the population in the sub-Saharan Africa was already having access to mobile devices [34]. Moreover, various research works [see 11-12, 35-36] have established growing levels of access to mobile phones in the continent. Such growing access to the mobile has been called Smartphone revolution which is susceptible to facilitate not only e-cultures proliferation such as mobile governance (mgovernance) but also citizen diplomacy and digital diplomacy. As the founder of Icon Capital Partners, Mohindra Rajan (cited in Knowledge @ Wharton) concedes that, the increasing mobile connectivity witnessed in sub-Saharan countries actually points to the fact that, phenomena such as digital diplomacy, citizen diplomacy, e-participation and mobile governance (m-governance) will eventually surpass eGovernance in the years to come [37]. He notes that: We feel that eventually [the] mobile is going to overtake [the] electronic because of the penetration of mobiles. Africa has never had landlines in numbers comparable to other parts of the world. Today, most of the mobile devices are smartphones. It's surprising, looking at the per capita income, but the smartphones are overtaking the normal phones. And the way smartphones are becoming cheaper by the day, we feel mobile government is the future. [37, p.45]

It goes without saying that growing levels of Internet and social media penetration coupled with rising mobile connectivity and high accessibility to Smartphones augur better developments in African digital diplomacy. Digital diplomacy is based on the use of ICTs. Any development in favor of their proliferation on the continent can only be an opportunity for digital diplomacy.

\subsection{The (Re)Emergence of the Post Truth Era}

At first look, this factor merits to be treated as a challenge. But it is the conviction of this author that the post truth era is viewable as a challenge-turnedopportunity for African digital diplomacy. This is so as the post truth phenomenon has these last years motivated African governments, MFAs and embassies to increasingly resort to social-media driven communications to neutralize fake news or alternative facts that could tarnish their image on the international scene. There exist many examples of African governments, Heads of States/government, senior officials, embassies and diplomats that have, on the fly, deployed Internet based communications to debunk alternative facts around their countries or their activities; thereby laundering the image of their countries or inciting favorable attitudes from foreign publics or diasporic communities. Examples will be provided in the following paragraphs.

First and foremost, what is the so-called post truth era and how does it affect digital diplomacy? The term "post truth" denotes a situation where public opinion and popular discourse in a society are shaped less by objective facts than by personal beliefs and appeal to emotions. The term thus denotes a situation where humanity thinks less about facts and bases its perception of the world on personal beliefs and emotional instincts. Such a scenario unavoidably leads to the social discourse and the public opinion being fuelled or driven by "alternative facts" which could be fake news. Going by this understanding of the term, one can consider the post truth era to be an era driven by alternative facts as well as an era where just anything (correct or not correct) can become true. According to historian Harari, it is an era where "not 
just particular facts but entire histories might be faked" [38-39].

Post truth or alternative facts are in no way new to mankind since issues such as propaganda and misinformation have characterized human history. However, the present era has been branded a post truth one. This has mainly been because of the perceptible ways in which the ubiquity of the Internet and the social media has facilitated the explosion of alternative facts, fake news or post truths. Indeed, the digital age - in which we are - has through the explosion of the Internet and social media communications, blurred lines existing between truth and what should be considered false or faked. The great influx and volume of information available on an issue always make it difficult for information consumers to sort facts from alternative truths as well as what is provable from what is improvable. This has seriously affected the function of diplomats all over the world as well as in Africa. The post truth era has for instance motivated diplomats to get ahead of events and to respond to alternative truths/facts in real time. Such an era also forces or warrants MFAs, embassies and foreign policy professionals to react to events (particularly fake news) on the fly to limit damages and protect the image of their countries or institutions in the national or international scene.

In Africa, many governments and MFAs have at various given circumstances resorted to such prompt social media-assisted approaches to neutralize fake news susceptible to damage the image of their countries or institutions on the international scene. During the recent wave of xenophobic attacks on foreign nationals in South Africa for instance, most African diplomats deployed social Facebook and WhatsApp-based communications to counter the various waves of fake news and disinformation that aimed to exaggerate South Africans' xenophobic attacks and cause violent retaliations from African communities that were affected by these attacks. South African President Cyril Ramaphosa for instance has led many social media-based efforts to patch up the image of his country on the African continent and protect foreign investment.

In early 2019, the Nigerian separatist group Indigenous People of Biafra (IPOB) launched an online propaganda campaign christened "Stop Christian Killing". This propaganda campaign which was based on false allegations of a Christian genocide in Northern Nigeria, caught the attention of the Nigerian government [40-41]. The latter reacted swiftly through both offline and online communications destined to the international community and countered the false allegations. The Nigerian government's move was aimed at laundering its image and that of Nigeria on the international scene. A similar situation occurred in Cameroon in 2018 when a separatist group called Ambazonia Defense Force deployed a variety of Twitter and
Facebook based communication claiming that the Cameroonian army is using untold violence against Anglophone civilians in the English speaking zones of the country [42-43]. The group used its Twitter and Facebook accounts to disseminate gory images of presumed Cameroonian men in uniform summarily executing unarmed civilians and burning down entire villages in the Anglophone zones of the country. The Cameroonian government reacted through online platforms such as Facebook and WhatsApp to debunk the claims and give its own version of the story to the international community and the Cameroonian Diaspora all over the world. Thus, the post truth era has been a challenge-turned-opportunity for digital diplomacy in Africa.

\section{Conclusion}

From many indications, the future of African digital diplomacy is not as bleak as an Afro-pessimist observers may want the world to believe. The low levels of Internet and social media penetration, the poor digital diplomacy policies and the prevalent second level digital divide between African diplomats and their counterparts from the west strongly suggest that virtual diplomacy in the continent may not be as advanced as it is in western climes. However there exist a handful of concrete proofs which also suggest that African governments, MFAs and diplomatic missions are increasingly seeing the need to embrace more sophisticated forms of digital diplomacy. The current COVID-19 pandemic has obliged many of these African governments, MFAs and diplomatic missions to rethink their attitude towards digital diplomacy. The pandemic has in effect, forced them to leapfrog into an era of digital diplomacy where they are increasingly compelled to go beyond the usual "novice-culture" of just creating websites and Facebook or Twitter accounts that are poorly designed, irregularly updated and irregularly used for the purpose of engaging with foreign publics and Diasporic communities. The COVID-19 pandemic coupled with the acceleration of the smart society concept has plunged them into the pool of digital diplomacy, and overnight, the world saw how African Heads of governments, senior officials and diplomats mano militari scrambled to make such paradigms as virtual bi/multilateral meetings as well as teleconferencing common idioms and conventional tools in their practice of diplomacy. The adoption of lockdowns and social distancing policies as a result of the outbreak of the COVID-19 pandemic forced African countries' embassies to seriously think of rooting the bulk of their routine in the use of ICTs. Thus, in such a short span of time, many African countries embraced WhatsApp-based approaches as well as other Internet-based tools to attend to their citizens' needs. 
In the same way, the COVID-19 pandemic sparked a revolution in African digital diplomacy, the present post truth era has come to force African governments, MFAs and embassies to be more disposed to deploy Twitter, Facebook or WhatsApp-based communications in view of neutralizing online fake news or disinformation and ultimately laundering their image before foreign publics and Diasporic communities. These last years, African embassies and MFAs have, on the fly, debunked fake news and sought to give their own perspectives on controversial issues using Facebook or Twitter-assisted communications. All these changes are positive developments which augur good or better days for digital diplomacy on the African continent. However, there is still need to set better mechanisms that will enable the continent's digital diplomacy to flourish and be as laudable as the one observed in the West.

From many indications, African diplomats have mano militari leapfrogged into an era of more sophisticated forms of digital diplomacy without a robust planning. The major innovation in their digital diplomacy practices has mainly be transition from physical conferencing to virtual conferencing. There is therefore need for them to envisage digital diplomacy beyond this form of e-diplomacy. This entails proper training of diplomats (senior MFAs and embassies' staffers) in digital diplomacy through short-term capacity building initiatives. Such shortterm initiatives may equip diplomats already serving at embassies or MFAs with ready-to-deploy aptitudes. The introduction of digital diplomacy courses in universities should also be envisaged. Such courses have the potential of molding new generations of aspiring diplomats so that they be acquainted with the most recent currents in the field of diplomacy as a whole.

In addition to training, there is need to encourage research in digital African diplomacy as well as collaboration between African diplomats and digital diplomacy scholars. It is more and more axiomatic that African digital diplomacy is still a less explored path. Most scholars have devoted their attention to western digital diplomacy. Various aspects of the phenomenon in Africa - notably digital fluency among African diplomats, citizen diplomacy's impact on African countries' foreign policy and the like - are still not fully understood. Only well administered research can help address the many gaps in knowledge related to the field. Thus, African countries should sufficiently invest in research in this field. At least, they should work with (African) digital diplomacy academics and digital diplomacy experts in the development of their foreign policies. This will mean adopting an "open policy formation" rather than an absolute top-bottom approach to policy formation. By the "open policy formation" approach, digital diplomacy experts and scholars will be brought into the African states foreign policy-making. By such approach to foreign policy making, African governments will need to see these external entities (digital diplomacy experts and scholars) as relevant sources of expertise from which they can tap to develop an innovative policy and philosophy of work within theirs MFAs and embassies.

\section{References}

[1] Hocking B. and Mellisen, J. (2015). Digital Diplomacy in the Digital Age. The Hague: Clinhendeal Institute.

[2] Al-Muftah, H. et al (2018). Factors, Influencing eDiplomacy Implementation: Exploring CausalRelationships Using Interpretive Structural Modeling. Government Information Quarterly, 35(3), pp. 502-514.

[3] Melissen, J. (2005). The New Diplomacy: Between Theory and Practice. In Melissen Jan (ed), The New Public Diplomacy. Soft Power in International Relations, (pp.327), Hampshire: Palgrave Macmillan.

[4] Porter, R. (2019). What is Smart City Development. Africa Housing News. Retrieved June 20, 2020 from https://africahousingnews.com/2020/01/29/what-is-smartcity-development/

[5] Flanagan, M. (2015). 'Foreword'. In Digital Diplomacy \& the \# G8. (p.2-3), London: Portland.

[6] Heinbecker, P. and S. Palamah. (2013). Constructive Powers Initiative: Internet Governance, Cyber Security and Digital Diplomacy, Toronto: CIGI.

[7] Netherlands, Institute of International Relations (2015). Diplomacy in the Digital Age. Clingedael Report. The Hague: Clingendael Institute.

[8] O.S. Adesina (2017). Foreign Policy in an Era of Digital Diplomacy. Cogent Social Sciences, 3, pp. 1-13.

[9] N.E. Nweke (2012). Diploamcy in Era of Digital Governance: Theary and Impact. Information and Knowledge Management, 2(3), pp.22-26.

[10] Mvai, C. (2019). Africa: Smart Cities to Drive Urbanization. News Times, October 31, edition, pp.45-56.

[11] Manor, I. (2016). Are we there yet: Have MFAs Realized the Potentials of Digital Diplomacy? Results from a Cross National Comparison. The Diplomacy and Foreign Policy 1(2), pp.1-26.

[12] Endong, F.P.C. (2018). Social Media Networking and the Future of Public Diplomacy in Africa: Insight from Recent Research and Case Studies. In Swati Bute (Ed), Media diplomacy and its evolving role in the current geopolitical climate, (115-137), Hershey, PA: IGI Global.

[13] Manor, I. (2018). The Digitization of Public Diplomacy. Cham: Palgrave.

[14] Kampf, R., Manor, I. \& Segev, E. (2015). Digital Diplomacy 2.0? A Cross-national Comparison of Public 
Engagement in Facebook and Twitter. The Hague Journal of Diplomacy, 10(4), 1-26.

[15] Wekesa, B. (2020). CCOVID-19 Heralds the Era of Digital Diplomacy in Africa. CPD Blog. https://www.uscpublicdiplomacy.org/blog/covid-19-herald s-era-digital-diplomacy-africa. (Access date: June 20, 2020).

[16] Mahler, D. G.; Montes, J. \& Newhouse, D. L. (2019). Internet Access in Sub-Saharan Africa (English). Poverty \& Equity Note; no. 13. Washington, D.C.: World Bank Group.

[17] Twiplomacy (2019). World Leaders on Twitter. Twiplomacy. https://twiplomacy.com/info/africa/. (Access date: June 15, 2020)

[18] ECOWAS (2020). Final Communique: Extraordinary Session of The Ecowas Authority of Heads Of State and Government (Videoconference, 23rd April 2020). Abuja: ECOWAS

[19] East Africa Community (2020). Heard of States Consultative Meeting of the East Africa Community. https://www.eac.int/communique/1725-communiqu\%C3\% A9-heads-of-state-consultative-meeting-of-the-east-african -community. (Access date: June 16, 2020).

[20] Stanzel, V. (2018). New Realities in Foreign Affair: Diplomacy in the $21^{\text {st }}$ Century. SWP Research Paper.

[21] E. Benyan. (2016). Ethiopia's Foreign Affairs Heading towards Full-Fledged Digital Diplomacy. The State of Digital Diplomacy 2016.https://www.sodd16.com/ethiopias -foreign-affairs-heading-towards-full-fledged-digitaldiplomacy-benyam-ephrem/. (Access date: July 23, 2020).

[22] Alliance for Affordable Internet (2016). World OffTrack to Achieve UN Internet Access as Broadband Prices Remain High. New York: Alliance for Affordable Internet (A4AI).

[23] ITU (2019). Measuring Digital Development. Facts and figures, Geneva: ITU.

[24] Dahir, A. L. (2017). Government Dithering Prevents Millions of Africans from Accessing the Internet. Quartz Africa, February edition. 21-27.

[25] Sarmah, S. (2014). Fighting the Endless Spread of Ebola Misinformation on Social Media. Fast Company, https://www.fastcompany.com/3034380/fighting-theendless-spread-of-ebola-misinformation-on-social-media. (Access date: May 9, 2020)

[26] Rashika, V. (2018). The Benefits and Risks of Digital Diplomacy. SEEU Review, 13(1), pp. 75-89.

[27] Freedom on the Net (2016). Silencing the Messenger: Communication Apps under Threat. London: Freedom House.

[28] Freedom House (2015). Freedom on the Net 2015. Nigeria. London: Freedom House.
[29] ITU (2017). Question 1/2: Creating the Smart Society: Social and Economic Development through ICT Applications, Geneva: ITU.

[30] Transform Africa Summit (2013). Smart Africa Manifesto, Kigali: Transform Africa Summit.

[31] Kemp, S. (2018). Digital in 2018: World's Internet Users Pass to 4 Billion. Special Reports, New York: We are Social.https://wearesocial.com/blog/2018/01/globaldigital-report-2018.

[32] Internet World Stats (2019). Internet Users Statistics for Africa. https://www.internetworldstats.com/stats1.htm. (Access date: March 5, 2020).

[33] We are Social \& Hootsuit (2020). Digital 2020. Global Digital Overview. New York: We are Social \& Hootsuit.

[34] Fraser-Molekiti, G. and Senghor, D. (2010). Egovernance and Citizen Participation in West Africa: Challenges and Opportunities. Dakar: The Panos Institute \& The United Nations Development Program.

[35] Hafkin, N.I. (2009). E-government in Africa: An Overview of Progress Made and Challenges. A Paper Presented at the UNDESA/UNPAN Workshop on Electronic/Mobile Government in Africa, held, from 17-19 February, 2009.

[36] Cox, K. et al (2019). Social media in Africa: A Double Edge Sword for Security and Development. Cambridge: United Nation Development Program (UNDP).

[37] Wharton University (2016). Building e-Governance in Africa: One Pioneering Company's Approach. Knowledge @ Wharton, August 23 edition, 43-49.

[38] Harari, Y.N. (2018a). Homo Dues. A Brief History of Tomorrow. New York: Harper.

[39] Harari, Y.N. (2018b). Sapiens. A Brief History of Mankind. New York: Harper.

[40] Home Office (2020). Country Policy and Information Note. Nigeria: Biafran Separatist. London: Home Office.

[41] Nwofe, S.E. and Goofall, M. (2019). The Web as an Alternative Resource for Pro-Biafra Independent Movement in Nigeria: The Case of Indigenous People of Biafra. Athens Journal of Mass Media and Communication, 5(1), pp.51-72.

[42] Sombaye, E.J.R. (2019). Inside the Virtual Ambazonia: Separatism, Hate Speech, and Diaspora in the Cameroonian Anglophone Crisis. An MA Thesis submitted to the University of San Francisco.

[43] Defy Hate Now (2020). Social Media Hate Speech Mitigation. Cameroon Field Guide. Berlin: Open Culture. 